\title{
DIRETRIZES PARA A INCLUSÃO DE PESSOAS CEGAS EM MUSEUS
}

\author{
Adriana Bolaños-Mora \\ Universidade Federal do Rio Gande do Sul \\ adrianabmora@gmail.com \\ Airton Cattani \\ Universidade Federal do Rio Gande do Sul \\ aacc@ufrgs.br \\ Filipe Campelo Xavier da Costa \\ Universidade do Vale do Rio dos Sinos \\ filipecxc@gmail.com
}

\begin{abstract}
Resumo: A predominância visual nos museus sugere uma mudança de parte dos profissionais encarregados de projetar estratégias comunicacionais, visando assim a inclusão de pessoas cegas nestes espaços, pois esta realidade gera dificuldades para usufruí-los. Esta pesquisa pretende abordar as possibilidades do design, para contribuir na diminuição do afastamento ou frustração de pessoas cegas quando estão em um museu. A partir da pesquisa fenomenológica, a experiência pessoal do cego e quatro exibições latino-americanas estudadas, foi construído um referencial das possibilidades de gerar inclusão através da geração de experiências sensoriais. Para isto, foi feita uma réplica de uma peça de museu, que além de poder ser tocada, foi complementada com audiodescrição. A análise dos dados permitiu identificar diretrizes que ao implementá-las ofereçam ao público cego a chance de fazer a visita com independência e desfrutá-la junto com quem enxerga, contribuindo assim para que esse momento seja inesquecível.
\end{abstract}

Palavras-chave: Estímulos sensoriais, Inclusão em museus, Deficiência Visual, Pessoas cegas, Experiência inclusiva.

\section{INTRODUÇÃO}

Os museus constituem-se em importantes repositórios de aspectos da cultura universal. Com várias especialidades, estes locais armazenam, catalogam, estudam e exibem artefatos das mais variadas procedências, permitindo seu acesso ao público de maneira organizada e orientada. Mais do que um simples local de guarda, os museus têm expandido suas atividades de modo a contemplar vários aspectos relacionados 
com os objetos que guarda e mostra. Programas educativos destinados a público em geral ou específico (por exemplo: estudantes, idosos, deficientes), contribuem para a ampliação do conhecimento que se tem sobre os objetos apresentados. Nesse sentido, o design, em suas várias modalidades, tem muito a contribuir com os aspectos museológicos. O design de exposições, por exemplo, preocupa-se com a experiência do público em ambientes museais, procurando tornar a visita a um museu algo mais que a simples contemplação de obras. Para isso trabalha de modo integrado aspectos arquitetônicos, de segurança, estruturais, curatoriais, gráficos etc. Mas existe uma característica comum a todos estes intervenientes: seu aspecto visual, já que todas essas manifestações devem ser vistas para ser plenamente apreendidas pelo público visitante. Neste momento uma pergunta se impõe: e como é a experiência de um cego ao visitar um museu? Modernamente existe uma salutar preocupação acerca das questões que envolvem a acessibilidade física para parcelas da população que até então não eram consideradas como usuários de espaços culturais, como cadeirantes e outros deficientes (CARDOSO; CUTY, 2012). E os cegos? Como podem usufruir um ambiente de exposições cuja característica principal costuma estar no fato de serem eminentemente visuais? Que aspectos devem ser levados em conta no projeto de uma exposição onde a presença de pessoas cegas entre o público seja considerada?

Este artigo trata especificamente da inclusão de pessoas cegas a museus. Partindo da pesquisa fenomenológica a partir da observação de exposições onde a presença de cegos foi levada em consideração, e da experiência pessoal do cego por meio de um experimento, se construiu um referencial das possibilidades de gerar inclusão, através da geração de experiências sensoriais. São apresentadas diretrizes que podem contribuir para que a experiência de cegos ao visitar uma exposição em um museu possa ser um fato significativo para a vida dessas pessoas e para sua maneira não visual de experenciar o mundo.

Mas como consegui-lo quando o público alvo são pessoas cegas? O fato de que a linguagem visual ainda é a forma de comunicação predominante nas estratégias de comunicação museológica, principalmente para salvaguardar os objetos da degradação, faz com que haja um distanciamento real e físico entre o objeto exposto e o visitante. Na grande maioria das exposições é proibido tocar nos objetos expostos e, como consequência, a pessoa cega enfrenta dificuldades em usufruir plenamente destes espaços, uma vez que o tato é um dos sentidos mediante o qual o cego "vê" o mundo. Os sentidos humanos desempenham um papel importante na compreensão e experiência que as pessoas têm em relação aos objetos que as cercam. Vemos, ouvimos, cheiramos e tocamos os artefatos que nos rodeiam de modo a aprender mais sobre eles, mas também para experimentar as sensações em si. Com ênfase na concepção de produtos que atendam não apenas o caráter utilitário, mas também requisitos afetivos, epistêmicos e hedônicos, nota-se um crescente interesse no desenvolvimento do chamado design sensorial, ou seja, aquele que leva em consideração especificamente os sentidos humanos (DAGMAN; KARLSSON; WIKSTRÖM, 2010).

Projetar uma exposição ou mesmo um museu para desfrutá-los com os vários sentidos humanos requer não somente bom senso e conhecimento técnico, mas 
também o conhecimento de outras experiências similares que tenham tido sucesso ou, ainda melhor, a própria experiência do usuário e sua vivência diária. Sendo esse usuário uma pessoa cega, sua experiência/vivência será fundamental para subsidiar a equipe no processo de projeto. Segundo Dias de Sá (2002), a falta da visão produz uma reorganização dos sentidos e das funções mentais, o que faz com que pessoas cegas tenham destreza tátil, discriminação auditiva, olfativa, raciocínio, memória e capacidade verbal desenvolvidas de maneira diferente das pessoas videntes. Contudo, as abordagens e representações em torno da perda da visão e das pessoas cegas geralmente concentram-se em suas limitações, dificuldades, obstáculos, restrições, impedimentos ou incapacidades. Ainda segundo o autor, dificilmente o potencial positivo, representado por outras habilidades, estratégias e diferentes esquemas da experiência não visual, são compreendidos ou devidamente valorizados e incorporados como diretrizes de projeto. Assim, projetar ações de inclusão de pessoas cegas em museus demanda um trabalho interdisciplinar por parte de todos os envolvidos no projeto. Press e Cooper (2009) defendem que "projetar a experiência supõe considerar as pessoas em primeiro plano, contemplar o mundo através de seus olhos e sentir com seus sentimentos". Mas cabe salientar que o elemento principal deve ser o usuário final, devendo toda a equipe aproximar-se dele, de modo a conhecer suas experiências anteriores e procurar entender como ele sonha com esse museu ou exposição ideal.

Atualmente, a maioria dos profissionais de design de exposição afirma que as pessoas com deficiência visual, entre outros, têm o direito de ter acesso à informação e ao patrimônio, mas ainda são escassas as iniciativas de inclusão nestes espaços. Essa questão também merece uma reflexão sobre a mudança de atitude da sociedade em relação às pessoas com deficiências (CARDOSO; CUTY, 2012). Assim, com o intuito de contribuir para a aproximação de pessoas cegas com o ambiente museal foi desenvolvido um estudo em que procurou-se sistematizar diretrizes para ações que visem incluir pessoas cegas como visitantes de um museu ou exposição. Para tanto, optou-se por um estudo fenomenológico que permitisse evidenciar as necessidades de adaptação que deve ter uma exposição que pretenda ser inclusiva para pessoas cegas, a partir da experiência desses usuários em particular. Com ênfase na experiência de vida da pessoa cega na sua visita ao museu, o método de pesquisa fenomenológica é apropriado por suas características qualitativas, pois foca-se no ser humano como agente, na qual sua visão do mundo é o que realmente interessa, e como o contexto influencia na formação de experiências (GIL, 2010; MERLEAU-PONTY, 2006; PINE, GILMORE, 1998), levando em conta que estas podem ser positivas ou negativas. Mesmo que a pesquisa fenomenológica não deva ser vista como algo rígido, é possível tomar como referência o seguinte roteiro (GIL, 2010): primeiro momento (préreflexivo), formulação do problema, seleção dos participantes, escolha da técnica de coleta de dados, coleta de dados, análise dos dados e redação do relatório.

O resultado da análise dos casos pesquisados e as assertivas significativas encontradas entre os sujeitos descrevem padrões comuns da experiência, ao mesmo tempo em que podem se constituir como referentes que permitem identificar e categorizar os fatos para que uma exposição possa se tornar inclusiva, bem como sistematizar diretrizes para ações de inclusão de pessoas cegas em museus. A seguir 
são apresentadas as condições em que se desenvolveu o experimento, por meio do qual foi possível traçar diretrizes para a inclusão de pessoas cegas em ambientes de museu.

\section{DESENVOLVIMENTO}

\subsection{Primeiro momento (Pré-reflexivo)}

Neste momento, o problema de pesquisa ainda não está bem definido. Ele corresponde mais a uma insatisfação do pesquisador em relação àquilo que ele pensa saber sobre algo. Algo o incomoda, gerando uma tensão que o leva a buscar a essência do fenômeno (GIL, 2010). Neste caso específico, o problema era procurar entender como uma pessoa cega pode usufruir de uma exposição em ambientes de museu de características predominantemente visuais. Assim, foram estudadas quatro exibições latino-americanas que tinham como ênfase a participação de cegos entre os visitantes: a exposição Tocar, mirar, sentir realizada no Centro Cultural da Pontifícia Universidade Católica do Equador - PUCE com o apoio do Museu do Louvre, França; a sala SensoPerceptiva do Centro Metropolitano de Quito, Equador; a exposição Bandas populares no Museu da Cidade de Quito, Equador; e a exposição de maquetes táteis $A$ arte de sentir, em Porto Alegre, Brasil. Estes eventos ocorreram entre 2010 e 2011.

A partir dessas exibições se construiu um referencial das possibilidades dos estímulos sensoriais para possibilitar inclusão e integração das pessoas cegas no ambiente do museu. Observou-se que a utilização de outros sentidos além da visão era uma característica comum. Como resultado desta etapa pré-reflexiva, se aprimorou a consciência do fenômeno a estudar, facilitando o desenvolvimento de um olhar mais sensitivo e concreto sobre o tema. Este referencial permitiu constatar que os estímulos sensoriais podem complementar a experiência não visual do cego, com especial ênfase nos táteis e auditivos, uma vez que o potencial positivo das habilidades, estratégias e diferentes esquemas da experiência não visual são compreendidos, explorados ou devidamente valorizados em ambientes de exposições, mas que podem ser aproveitados como ferramentas de inclusão.

\subsection{Formulação do problema}

Após analisar estes casos, foi possível estabelecer um referente de experiências voltadas para a inclusão e sensibilização da comunidade em geral, o qual serviu de base para definir a pergunta-problema:

Como, por meio de um estudo fenomenológico, se pode conhecer a essência da experiência do cego em sua visita a um museu, de modo a fornecer subsídios para ações de Design e inclusão social?

\subsection{Seleção dos participantes}

Para a seleção dos participantes desta pesquisa, não foram consideradas características como gênero, idade ou nível de formação, e muito menos foi considerada a causa da cegueira, baseados na experiência de Csikszentmihalyi (1991), quem afirma que depois de milhares de indivíduos pesquisados, as experiências ótimas eram descritas do mesmo modo, sem importar o gênero, a idade ou as diferenças culturais. Foi levada em conta a disponibilidade dos sujeitos de participar da pesquisa, para garantir sua participação e expressão espontânea na hora de comunicar seus 
sentimentos e emoções ao longo do estudo. O número de pessoas entrevistadas dependeu do processo de "saturação teórica" (MORSE, 2000), que consiste na realização progressiva das entrevistas até o ponto em que os dados obtidos vão se tornando repetitivos. Para esta pesquisa foram entrevistadas quatro pessoas cegas, entre os 25 e 45 anos.

\subsection{Instrumento de coleta de dados}

$O$ instrumento utilizado foi a entrevista semi-estruturada, que permitiu a livre expressão dos entrevistados, essencial para a descrição da experiência vivida. Tanto o agendamento das entrevistas quanto os locais nos quais elas ocorreram, foram propostos conforme disponibilidade dos participantes, três realizadas em cafés da cidade, e um só que pediu para ir até sua casa. A entrevista estava dividida em três partes:

O quadro 1 apresenta a primeira parte, que considerou uma série de perguntas introdutórias para descrever sentimentos e até recordações de experiências passadas ao visitar museus.

Quadro 1 - Primeira parte da entrevista.

\begin{tabular}{|l|l|}
\hline \multicolumn{2}{|l|}{ Conta-me sobre você... } \\
\hline Nome: & \multicolumn{1}{l|}{ Idade: } \\
\hline Nível Formação: & \multicolumn{1}{l|}{ Causas da cegueira: } \\
\hline 1. & Que atividades de lazer acostuma a fazer? \\
\hline 2. & O que você pensa, sente ou lembra, com relação à idéia de ir a um museu? \\
\hline 3. & Alguma vez já se sentiu excluído por ser cego (a)? \\
\hline 4. Já conheceu algum museu ou exibição inclusiva? \\
\hline 5. Conheces algum museu inclusivo, seja em Porto Alegre, ou outra cidade? \\
\hline
\end{tabular}

Fonte: Elaborado pelo autor, com base na pesquisa realizada.

A segunda parte possibilitou a manipulação tátil de uma peça acompanhada de audiodescrição. Para tanto foi usada uma réplica (ver quadro 2) em escala 2:1 de uma peça antropomórfica de joalheria pré-colombiana, cujo original se encontra no acervo do Museu do Ouro, em Bogotá, Colômbia. Esta mantém características como materiais e métodos de fabricação da original, o que preserva a informação que o cego vai receber pelo contato com as suas mãos. A intenção foi simular como seria a aproximação da pessoa a uma peça de museu, o que facilitaria a identificação de dificuldades, facilidades, e sugestões resultantes de esta interação.

Quadro 2 - Caracterização da original em relação à réplica.

\begin{tabular}{|l|l|l|}
\hline Homem-morcego & Original & Réplica \\
\hline
\end{tabular}




\begin{tabular}{|l|l|l|}
\hline Fotos & \\
& \\
\hline Dimensões & $5,2 \times 7,2 \mathrm{~cm}$ & Pscala 2:1 \\
\hline Localização & $\begin{array}{l}\text { Acervo do Museu do Ouro } \\
\text { (Colômbia) }\end{array}$ & PGDesign - UFRGS (Brasil) \\
\hline Material & $10 \%$ ouro e 90\% cobre & 40\% zinco e 60\% cobre \\
\hline Método de fabricação & Cera perdida & Cera perdida \\
\hline Ano de fabricação & Entre o ano 900 e 1600 & Ano 2011 \\
\hline Lugar de fabricação & Zona Tayrona (Colômbia) & Porto Alegre, RS. (Brasil) \\
\hline
\end{tabular}

Fonte: Elaborado pelo autor, com base na pesquisa realizada.

O quadro 3 mostra a terceira parte de formulação de perguntas, diretamente relacionadas à experiência vivenciada ao tocar a réplica pré-colombiana, escutar a audiodescrição e coleta de sugestões.

Quadro 3 - Terceira parte da entrevista.

6. Conta-me... Como foi tua experiência?

7. Conseguiste identificar a figura, se parece ela a alguma coisa que tu já conheceste? Já conhecias algo da cultura pré-colombiana?

8. E a tua experiência tátil, permitiu identificar a peça?

9. E enquanto à audiodescrição sim logrou complementar a tua experiência tátil?

10. O que consideras que faz falta para conseguir que este protótipo seja adequado para a sua própria compreensão? (tanto em design, quanto em ferramentas)

11. Se tivesses a oportunidade de participar na concepção ou reestruturação de um museu, quais seriam tuas propostas, para fazer dele um lugar inclusivo?

12. O quê representou para ti participar deste ensaio?

Fonte: Elaborado pelo autor, com base na pesquisa realizada.

\subsection{Técnica de coleta de dados}

Todas as entrevistas foram registradas em áudio, vídeo e fotografias, de modo a obter o registro daquilo que não é transmitido pelas palavras (por exemplo, o modo de interagir da pessoa com o objeto, gestos e outras expressões não verbais). Posteriormente foram transcritas literalmente e submetidas a sucessivas leituras e releituras, com o objetivo de encontrar assertivas significativas que contribuissem para resolver o problema de pesquisa. 


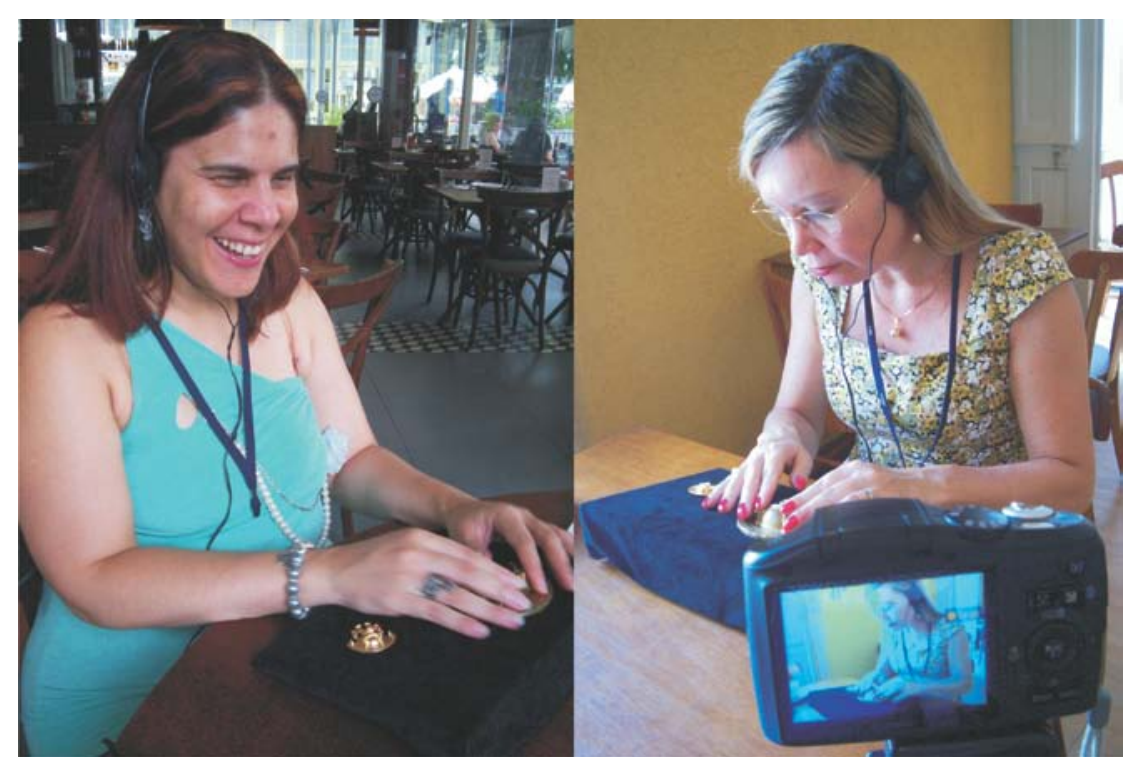

Figura 1 - Dois momentos de interação de cegos com as réplicas. Porto Alegre, Brasil. Fonte: Elaborado pelo autor, com base na pesquisa realizada.

\subsection{Análise fenomenológica dos dados}

Para facilitar a sistematização das assertivas significativas, foi elaborada uma matriz, na qual se agruparam em conjuntos de temas relacionados, tentando sempre não interferir na busca da descrição do fenômeno. As filas foram organizadas assim: caixas respectivas a cada sujeito pesquisado, considerações relacionadas às observações gerais (ou seja, afirmações que não envolviam nenhum dos cinco sentidos mas que os sujeitos fizeram questão quando relatada sua experiência), visão, tato e audição. Na última coluna se registraram os resultados da combinações de respostas.

Quadro 4 - Matriz de integração das assertivas significativas de cada protocolo ${ }^{1}$.

\begin{tabular}{|l|l|l|l|l|l|}
\hline Considerações relacionadas a: & Sujeito A & Sujeito B & Sujeito C & Sujeito D & Resultados \\
\hline Observações Gerais & & & & & \\
\hline Visão & & & & & \\
\hline Tato & & & & & \\
\hline Audição & & & & & \\
\hline
\end{tabular}

Fonte: Elaborado pelo autor, com base na pesquisa realizada.

A figura 2 mostra a matriz já preenchida, registrando e consolidando as declarações significativas dos protocolos, neste caso do sentido do tato. Isto para exemplificar o processo da sistematização dos dados.

\footnotetext{
${ }^{1}$ Cada uma das transcrições das entrevistas dos sujeitos pesquisados, segundo o modelo proposto por Colaizzi em Gil (2010)
} 


\begin{tabular}{|c|c|c|c|c|c|}
\hline \multirow{7}{*}{ 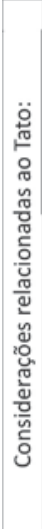 } & Sujeito A & Sujeito B & Sujeito C & Sujeito D & Resultados \\
\hline & \multirow{2}{*}{ 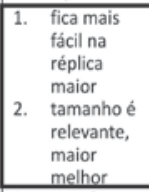 } & \multirow{3}{*}{\begin{tabular}{|l}
1. \\
Eu acho \\
que a \\
maior (ao \\
se referir \\
à réplica) \\
é bem \\
melhor \\
para notar \\
os \\
detalhes
\end{tabular}} & \multirow{4}{*}{$\begin{array}{l}\text { 1. As pessoas acham que é só o } \\
\text { toque, não, não é só o toque } \\
\text { tem que ter o entendimento, } \\
\text { cognição, elaboração. É } \\
\text { mais complexo do que isso. } \\
\text { 2. que a peças foram em } \\
\text { materiais como esse, por } \\
\text { exemplo, que eu pudesse } \\
\text { tocar e não danificasse elas. } \\
\text { Então acredito que as } \\
\text { réplicas elas ajudariam } \\
\text { bastante se fossem em } \\
\text { matérias resistentes. } \\
\text { 3. A experiência tátil foi muito } \\
\text { legall Muito interessante }\end{array}$} & \multirow{6}{*}{ 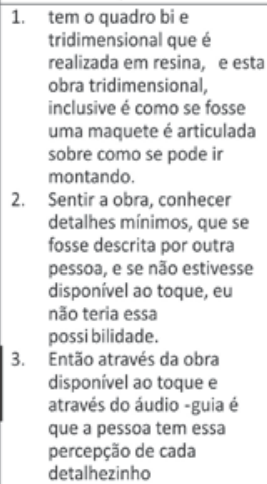 } & $\begin{array}{l}\text { (A) } 1+\text { (A) } 2+(B) 1+(C) 4 \text {.Uma réplica de tamanho maior é } \\
\text { bem melhor para notar os detalhes. }\end{array}$ \\
\hline & & & & & $\begin{array}{l}\text { (C) } 1 \text { As pessoas acham que é só o toque, não, não é só o toque } \\
\text { tem que ter o entendimento, cognição, elaboração. É mais } \\
\text { complexo do que isso } \\
\text { (A) } 3+\text { (C) } 2 \text { Os detalhes das peças podem se ressaltar com }\end{array}$ \\
\hline & \multirow{4}{*}{ 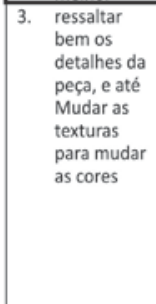 } & & & & $\begin{array}{l}\text { texturas diferentes, além disso que fossem feitas em materiais } \\
\text { resistentes que não s e danificassem com a manipulação. }\end{array}$ \\
\hline & & & & & $\begin{array}{l}\text { (C) } 3+\text { (D) } 2 \text { Ter uma obra disponivel ao toque será sempre } \\
\text { uma possibilidade muito interessante. } \\
\text { (C) } 5 \text { Falta cultura de toque. }\end{array}$ \\
\hline & & & $\begin{array}{l}\text { 4. Uma peça maior como esta, } \\
\text { os detalhes se ampliam, } \\
\text { ajuda mais }\end{array}$ & & $\begin{array}{l}\text { (D) } 3 \text { Ter uma obra disponivel ao toque mais o complemento } \\
\text { com outro sentido, vai ajudar na percepção. }\end{array}$ \\
\hline & & & $\begin{array}{l}\text { 5. a ialta de cultura mesmo, de } \\
\text { toque. }\end{array}$ & & $\begin{array}{l}\text { (D1. Podem se fazer quadros bi e tridimensionais, também } \\
\text { maquetes. }\end{array}$ \\
\hline
\end{tabular}

Figura 2 - Matriz das declarações referentes ao tato com marcação de assertivas relevantes para o estudo.

\section{RESULTADOS}

Fundamentadas nas considerações preliminares resultado da etapa exploratória, e associadas à análise das assertivas significativas de cada protocolo, foi possível propor diretrizes que podem contribuir para a inclusão de pessoas cegas em ambientes museais, apresentadas a seguir de maneira sistemática:

\subsection{Diretrizes em relação ao que se deve levar em conta ao iniciar ações de inclusão}

1. Reconhecer que a inclusão vai além das adaptações físicas e contempla também as relações pessoais. É indispensável treinar e capacitar a equipe de trabalho do museu em relação ao atendimento de públicos com cegueira;

2. Identificar que as ações de inclusão vão variar dependendo da natureza do museu, do tempo que vai durar determinada exibição, do orçamento disponível, entre outros;

3. Promover estratégias que convidem pessoas cegas, desde o início de qualquer iniciativa inclusiva, para contar com suas apreciações. Não se recomenda trabalhar baseados em pressupostos, já que isto poderia acarretar inconsistências comunicacionais que somente poderiam gerar efeitos negativos no visitante cego;

4. Saber como o cego pensa, sente e processa a informação que recebe pelos seus sentidos, e como isto vai fornecer informações aos museus que poderão se traduzir em ações inclusivas;

5. Concientizar-se de que a ausência de visão requer uma complementação sensorial, como consequência da reorganização dos sentidos por parte do cego;

6. Considerar que as ações de inclusão trazem como resultado inerente a integração daquele que enxerga com a pessoa cega;

7. Levar em conta as ferramentas que podem facilitar a sensação de autonomia na visita da pessoa cega (piso podo tátil e rampas, por exemplo).

\subsection{Diretrizes em relação aos estímulos sensoriais}


8. Analisar as vantagens e limitações que podem ter certas exibições com relação aos estímulos sensoriais envolvidos, para assim projetar levando em conta outros sentidos que podem complementar a experiência não visual do cego e mesmo de videntes;

9. Entender que as pessoas cegas também desejam conhecer características que, em um primeiro momento, podem parecer meramente visuais. Assim, a interpretação da informação recebida por meio dos outros sentidos vai complementar o processo pessoal e particular de cognição;

10. Procurar estratégias que convidem ao vidente a se sensibilizar e experimentar explorando outros sentidos;

11. Promover a cultura do sensorial, procurando proporcionar uma maior sensibilização e valorização para além do visual;

12. Entender que ao longo do processo de percepção não se recebem informações pelos sentidos de forma isolada. Sempre haverá complementação entre os estímulos. Portanto, deve-se levar em conta a possibilidade de fornecer mais elementos que ajudem o entendimento daquilo que não se está vendo.

\subsection{Diretrizes em relação aos estímulos do tato}

13.Gerar estratégias que favoreçam a aproximação de todos os públicos aos objetos de museu;

14.Considerar que a oportunidade de tocar os objetos (por exemplo, réplicas), atrai a atenção das pessoas, pois este fato ainda não é uma constante nos ambientes museais, o que pode gerar uma experiência memorável no visitante, independentemente de ser cego ou vidente;

15. Entender que a experiência da pessoa cega não fica completa apenas pelo fato de ter disponíveis objetos para tocar; o pleno entendimento é mais complexo do que o simples toque;

16. Considerar que no caso de uso de réplicas será necessário que: a) o material da réplica seja o suficientemente resistente para suportar o constante manuseio dos visitantes, sem se danificar; b) o tamanho da réplica seja adequado para ser facilmente manipulada com as mãos, além de permitir uma melhor percepção dos detalhes da peça; c) as texturas podem ser incluídas para ressaltar partes dos objetos, e também é importante que sejam similares às da peça original, para fornecer informação tátil relacionada com a temperatura e dureza do material; d) a escala real da peça seja mantida quando possível. Caso não seja possível, utilizar recursos que permitam apresentar a proporção do objeto real e a respectiva réplica, o que vai complementar a informação que o cego não consegue perceber; e) seja feita a manutenção constante dos objetos dispostos ao tato, tanto para controlar que estes não se danifiquem como para limpá-los; 
17. Entender que quando não é possível disponibilizar réplicas dos objetos de museu, deverá se compensar com o estímulo de outro sentido para complementar a experiência não visual;

18. Considerar que o material promocional da exibição utilize recursos inclusivos, como textos em Braille e estratégias de promoção em meios usados pelas pessoas cegas;

19. Levar em conta que ao fornecer textos em Braille será necessário: a) conhecer sobre os diferentes recursos que existem para gerá - los; b) o material (suporte) em que forem feitos os textos em Braille, deve considerar a durabilidade; c) a extensão dos textos impressos é mais curta do que os mesmos textos em Braille, em consequência deverá se pensar em que estes sejam curtos e concisos; d) os textos em Braille devem estar disponíveis ao tato, sem requerer esforço para conseguir tocá-los.

\subsection{Diretrizes em relação aos estímulos da audição}

20. Identificar que ao equipar o museu com recursos que estimulem a audição, estes podem ser: a) por meio do guia; b) por meio do áudio-guia; c) por meio da audiodescrição;

21. Os estímulos auditivos gerados pelo guia devem levar em conta que: a) é imprescindível a sua presença no percurso da visita da pessoa cega, pois ele vai complementar a informação recebida por outros estímulos sensoriais; b) o seu papel como mediador, já que pode confirmar em tempo real qualquer dúvida que a pessoa cega tenha em relação à informação recebida, não deixando espaço para dúvidas; c) treinar os guias no que concerne a questões do convivo com a pessoa cega pode ser o modo menos difícil de gerar estímulos de audição que complementem a experiência inclusiva; d) saber que a falta de contato real com os objetos do museu pode ser compensada com as respectivas descrições detalhadas que os contextualize no discurso museográfico;

22. Os estímulos auditivos gerados por meio de áudio-guias devem levar em conta que: a) o áudio-guia possibilita visita autônoma da pessoa cega, sem precisar da companhia de um guia; b) o áudio-guia facilita a visita em ritmo pessoal, em que a pessoa pode destinar mais tempo para avaliar e perceber cada obra conforme seus gostos; c) o áudio-guia pode ser fornecido por meio de fones de ouvido portáteis ou estar fixado próximo de cada obra e com comandos que permitam acioná-los quando forem necessários;

23. Os estímulos auditivos gerados por meio da audiodescrição devem levar em conta que: a) a complexidade de traduzir o visual em verbal exige a participação de um profissional bem preparado; b) o roteiro da audiodescrição e a equipe de trabalho geram resultados pontuais que para a pessoa cega possa ter confiança na informação recebida; c) a objetividade da audiodescrição possibilita a percepção de detalhes dos objetos que poderiam ser esquecidos por meio de outros estímulos audíveis; 
24. Reconhecer que, em geral, a pessoa cega precisa de várias impressões para construir a sua própria. Para isso o museu deve criar estratégias que facilitem, ao nível auditivo, diferentes registros de descrições que enriqueçam as imagens mentais que o cego constrói.

$\mathrm{O}$ atendimento a estas diretrizes pode contribuir para que a experiência de um cego ao visitar um museu seja memorável, uma vez que lhe propiciará informações complementares em relação aos objetos e obras apresentados. Com isso, amplia-se a possibilidade de que o ambiente museal torne-se relevante para estas pessoas desprovidas de um dos sentidos humanos, mas que, mesmo assim, têm condições de experenciar a seu modo ambientes de características marcadamente visuais.

\section{CONSIDERAÇÕES FINAIS}

A inclusão de parcelas da população que possuem algum tipo de deficiência à atividades usuais para outros segmentos ainda precisa percorrer um longo caminho. Em relação aos cegos e museus não é diferente. Mesmo grandes museus do mundo avançam timidamente neste quesito, muitas vezes limitando as ações acessibilidade a rampas de acesso físico e uma maquete tátil do edifício, o que é necessário, mas não suficiente. Já é possível observar na realidade brasileira um crescente avanço em direção à inclusão em ambientes culturais, de públicos com necessidades especiais que até então eram menosprezados. Também é possível observar estudos que visam contribuir para o oferecimento de condições favoráveis para inclusão de pessoas cegas. $O$ presente trabalho vai neste sentido, apresentando à comunidade acadêmica e outros segmentos ligados a ambientes expositivos, diretrizes as quais antes que serem únicas, definitivas ou dogmáticas, convidam a ampliar a discussão sobre a questão da inclusão de cegos em ambientes culturais. Assim, se tenta contribuir para que o processo de projeto de espaços culturais tenha características de inclusão inerentes e que esta não seja uma etapa posterior, onde forçosamente as adaptações são uma constante. Esta atitude vai se refletir em valores, crenças e significados compartilhados que se expressam em objetos materiais, serviços e atividades, o que para García-Canclini (2004) e Csikszentmihalyi (1991), geraria uma cultura específica, que nos ajuda a abordar desafios da existência, capazes de transformar forças e comportamentos e, em consequência, a significação na vida social.

Quem trabalha pela inclusão não deve pensar somente sob sua perspectiva ao gerar os espaços adaptados para o deficiente visual, mas também que deverá conviver com o cego, conhecê-lo e levar em conta sua maneira não visual de "ver" o mundo. Como enfatiza Souza (1997), qualquer ação que não leve em conta a intencionalidade e a disponibilidade de cada um em aceitar o outro pode levar boas intenções a distorções, confundindo o que realmente significa inclusão para um processo meramente integracionista.

\section{REFERÊNCIAS}

CAMARERO, Carmen; GARRIDO, Maria José. Fostering Innovation in Cultural Contexts: Market Orientation, Service Orientation, and Innovations in Museums. Journal of Service Research, 15 (1), 2012, p. 39-58. 
CARDOSO, Eduardo; CUTY, Jeniffer (Org.). Acessibilidade em ambientes culturais. Porto Alegre: Marca Visual, 2012.

CSIKSZENTMIHALYI, Mihály. Flow. The psychology of optimal experience. New York: Harper Collins, 1991.

DAGMAN, Jessica; KARLSSON, Marianne; WIKSTRÖM, Li. Investigating the haptic aspects of verbalised product experiences. International Journal of Design, v. 4, $n^{\circ}$. 3, 2010, p. 15-27.

DIAS DE SÁ, Elisabet. A bengala e a mulher invisível. In: MASINI, Elcie F. Salzano (Org.). Do sentido... pelos sentidos... para o sentido... Sentidos das pessoas com deficiências sensoriais. Niterói: Intertexto; São Paulo: Vetor, 2002. p. 27-32

GARCÍA CANCLINI, Nestor. Diferentes, desiguales y desconectados. Mapas de la interculturalidad. Barcelona: Gedisa, 2004.

GIL, Antônio Carlos. Como elaborar projetos de pesquisa. 5. ed. São Paulo: Atlas, 2010.

MERLEAU-PONTY, Maurice. Fenomenologia da percepção. 3 Edição. São Paulo: Martins Fontes, 2006.

MORSE, Janice M. Determining sample size. Qualitative Health Reseach, v. 10 na 1, p. 3-5, 2000.

PINE II, B. Joseph; GILMORE, James H. Welcome to the Experience Economy. Harvard Business Review, july 1998.

PRESS, Mike; COOPER, Rachel. El diseño como experiencia. El papel del diseño y los diseñadores en el siglo XXI. Barcelona: GGDiseño, 2009.

SCHMILCHUK, Graciela. El derecho a disfrutar del arte. Revista digital CENIDIAP. México, enero/abril, 2007.

SOUZA, Olga Solange Herval. A integração como Desafio: A (com) vivência do aluno deficiente visual na sala de aula. Dissertação (Mestrado em educação). Porto Alegre: Universidade Federal do Rio Grande do Sul - UFRGS, 1997.

THOMPSON, C. J.; LOCANDER, W. B.; POLLIO, H. R. Putting consumer experience back into consumer research: the philosophy and method of existential-phenomenology. Journal of Consumer Research, sep., 1989, p. 133-147. 